\title{
Salivary Gland Fistula
}

National Cancer Institute

\section{Source}

National Cancer Institute. Salivary Gland Fistula. NCI Thesaurus. Code C79715.

An abnormal communication between a salivary gland and another org an or anatomic site. 